\title{
On the Cover of this Issue: Multi-View Digital Image Correlation Systems for In-vitro Testing of Arteries from Mice to Humans by K. Genovese, P. Badel, C. Cavinato, B. Pierrat, M. R. Bersi, S. Avril, J. D. Humphrey
}

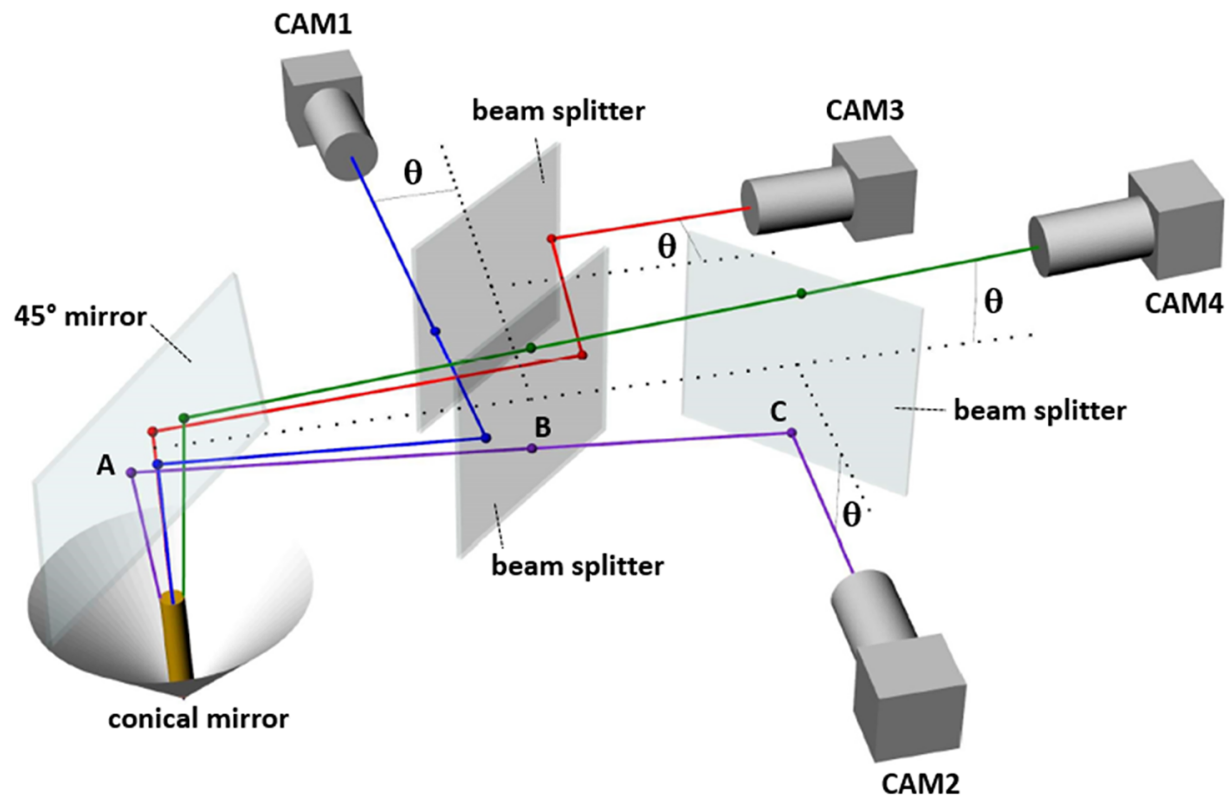

Multi-view digital image correlation systems for in vitro testing of arteries from mice to humans

by K. Genovese, P. Badel, C. Cavinato, B. Pierrat, M.R. Bersi, S. Avril, and J.D. Humphrey 